\title{
Clinical Reasoning: A 52-year-old woman with 3 weeks of progressive gait ataxia and dysarthria
}

Christine Lu, MD, * Lili Velickovic Ostojic, MD, * and Hernan Nicolas Lemus, MD

Neurology ${ }^{\circledR}$ 2018;90:e985-e989. doi:10.1212/WNL.0000000000005122

\author{
Correspondence \\ Dr. Lu \\ Christine.lu@mountsinai. \\ org
}

\section{Section 1}

A 52-year-old woman was admitted to the hospital with a 3-week history of progressive gait instability with multiple falls and slurred speech. She denied focal weakness, vision changes, cognitive decline, headaches, diplopia, or vertigo. No recent travels, change in medications, or illness were noted by the patient. Twelve years ago, the patient had been diagnosed with HIV and was initiated on treatment with ritonavir, atazanavir, and emtricitabine-tenofovir, but had not been compliant with her HIV medications. She was also diagnosed with hepatitis C, for which she received no treatment. She had smoked half a pack of cigarettes per day for the last 14 years and had a history of prior IV heroin use. She denied alcohol use.

Results of the general physical examination were remarkable for cachexia and a systolic murmur. Mental status examination was significant for impaired attention and memory and a cerebellar monotone dysarthria. Cranial nerve examination was significant for decreased sensation in the left V1-V3 distribution. Strength and tendon reflexes were normal, with flexor plantar responses. The patient had decreased sensation to pinprick in the left arm and leg. There was dysmetria bilaterally on finger-to-nose and heel-to-shin tests as well as overshoot on finger chase, worse on the left than on the right. The patient's gait was wide-based and ataxic. She also had a positive snout reflex.

\section{Question for consideration:}

1. How would you localize the lesion?

\section{GO TO SECTION 2}




\section{Section 2}

The patient's ataxia, dysmetria, and monotone dysarthria are suggestive of a cerebellar disorder, while impaired attention, poor memory, and a positive snout reflex could be localized to the frontal lobes. Her other symptoms such as left hemisensory loss to pinprick may be secondary to cortical, subcortical, or spinal cord pathology (i.e., spinothalamic tract). Overall, it is not possible to localize all of the above examination findings to a single lesion, and the patient does not appear diffusely encephalopathic from a systemic illness. Taken together, this presentation is suggestive of a multifocal process.
A CT head showed asymmetric lucency in the left middle cerebellar peduncle and corpus medullaris as well as the left frontal lobe. Initial laboratory work including a complete blood count, basic metabolic panel, and coagulation tests showed lymphopenia consistent with the patient's history of HIV not compliant with medications, but was otherwise unremarkable.

\section{Questions for consideration:}

1. What is your differential?

2. What additional tests would you order?

GO TO SECTION 3 


\section{Section 3}

The differential for subacute multifocal lesions in an immunocompromised patient is broad. In addition to diagnoses that would typically be considered in the general population, such as stroke or demyelinating disease, there is also the consideration for opportunistic infections and malignancy.

HIV is an independent risk factor for stroke, but the patient had no other known vascular risk factors except smoking to predispose her to recurrent strokes, and her history did not follow a clear pattern of stepwise deterioration. Given our patient's demographics, autoimmune inflammatory causes for recurrent stroke, specifically vasculitis, would be more likely. Other autoimmune etiologies, such as multiple sclerosis, acute disseminated encephalomyelitis, and other systemic rheumatologic diseases like systemic lupus erythematosus, sarcoidosis, and Sjögren disease with a CNS manifestation were also possible.

On the other hand, with our patient's immunocompromised status, infectious and oncologic etiologies had to be considered as well, especially as these diagnoses carry a grim prognosis. These include CNS lymphoma, progressive multifocal encephalopathy (PML), HIV encephalitis, tuberculosis (TB), cryptococcal, cytomegalovirus (CMV), and herpes simplex virus (HSV) infection, which present with a subacute (weeks to 3 months) decline in mental status along with focal neurologic findings. ${ }^{1}$

An MRI with and without contrast of the brain was obtained, which showed multiple patchy regions of $\mathrm{T} 2$ hyperintensity in the left middle cerebellar peduncle, bilateral corpus medullaris, and subcortical arcuate fibers in the left inferior frontal lobe, without restricted diffusion, mass effect, or contrast enhancement (figure).

Additional laboratory work in serum revealed a CD4 count of 56 cells $/ \mathrm{mL}$ and viral load of 5,873 copies/ $\mu \mathrm{L}$. Serum QuantiFERON gold, angiotensin-converting enzyme, Epstein-Barr virus (EBV), CMV antibodies, rapid plasma reagin, lipid panel, thyroid-stimulating hormone, and
Figure MRI of the brain with and without contrast
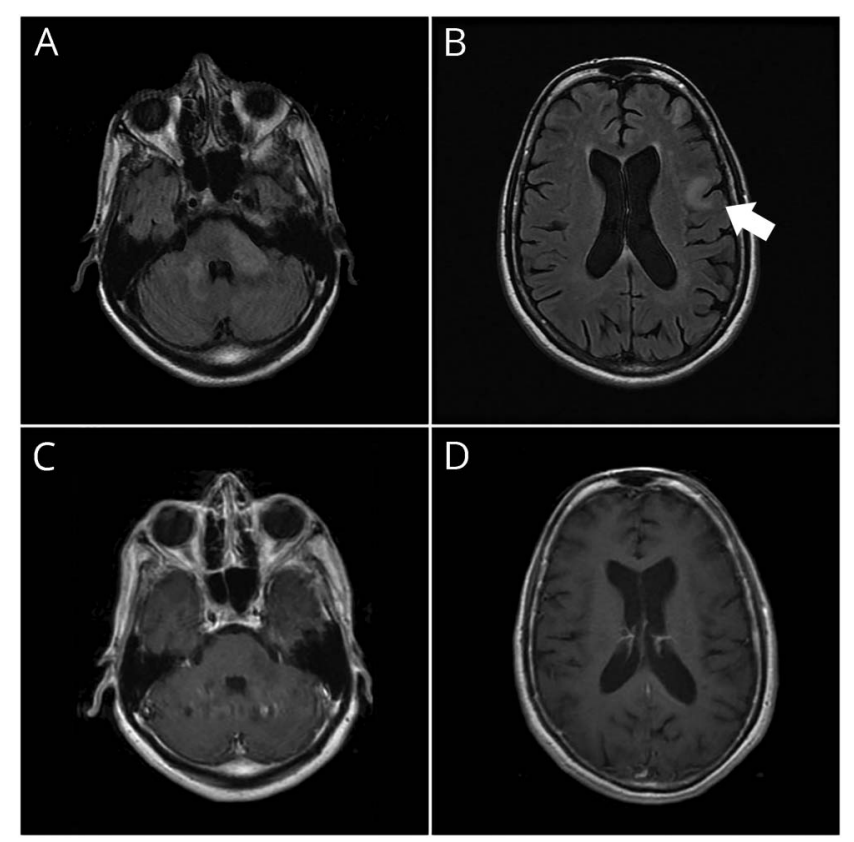

(A) Multifocal nonenhancing, T2 hyperintense lesions affecting the white matter on this T2 fluid-attenuated inversion recovery sequence are consistent with progressive multifocal encephalopathy (PML). Patients with AIDS with PML tend to have brainstem lesions more frequently, with a cerebrum to brainstem ratio of 4:1 compared to $10: 1$ in populations without AIDS. ${ }^{8}$ (B) $\mathrm{U}$ fibers (arrow) are subcortical lesions involving the arcuate fibers that appear U-shaped. ${ }^{9}$ (C, D) T1 postcontrast images.

hemoglobin A1C returned negative or within normal limits. Serum JC virus (JCV) was also negative.

A lumbar puncture was performed, and CSF revealed 0 white cells, glucose of 45 , and protein of 44 . CSF testing for TB, angiotensin-converting enzyme, EBV, CMV, HSV, varicella zoster virus, and syphilis screen was negative, but 111,136 copies/mL of JCV in CSF were detected by PCR.

\section{Questions for consideration:}

1. What is the diagnosis?

2. How would you treat the patient?

GO TO SECTION 4 


\section{Section 4}

PML is caused by a JCV reactivation infection of oligodendrocytes (and to a lesser extent astrocytes) leading to focal loss of myelin resulting in neurologic deficits. It is associated with conditions causing prolonged immunosuppression, including AIDS, chronic inflammatory disease, hematologic malignancies, organ transplantation, and treatment with immunomodulating therapies such as rituximab and natalizumab. The presentation is heterogeneous with focal or multifocal neurologic findings. Motor, sensory, cerebellar, and visual field deficits are common, whereas the optic nerve and spinal cord are usually spared. MRI of the brain classically reveals subcortical hemispheric white matter or cerebellar peduncle hyperintense lesions on T2 sequence without contrast enhancement or mass effect. ${ }^{2}$

Although the JCV quantitative PCR is highly sensitive $(>95 \%)$ and specific, ${ }^{3}$ our patient had a negative serum PCR. However, the high levels of JCV detected in the CSF are virtually diagnostic of PML. This highlights the importance of CSF analysis in patients where there is a suspicion for PML, regardless of serology.

There are currently no effective treatments for PML but survival can be improved by reversal of immunosuppression, which in AIDS consists of combination antiretroviral therapy
(cART). An in vitro drug screen detected anti-JCV activity with mefloquine and mirtazapine, but their effect has yet to be demonstrated clinically. The prognosis is poor and, although it depends on the localization of the lesions, the median survival has been reported as $0.4-1.8$ years after initiation of cART. ${ }^{4}$ Factors that confer a more favorable outcome include higher CD4 count, lower JCV load, and presence of JCVspecific cytotoxic T lymphocytes. ${ }^{5}$

The patient was discharged to a subacute rehabilitation facility, after being restarted on cART and with appropriate compliance. However, about 5 weeks after her initial presentation, she returned to the hospital with worsening mental status, weakness, and dysarthria. On examination, she was now only oriented to self, manifesting severe dysarthria, dysphagia, and a complete right-sided hemiplegia. Repeat CD4 count in serum was 50, but HIV viral load at this time was undetectable. A repeat MRI showed an increase in the areas of $\mathrm{T} 2$ hyperintensity previously seen in the pons, cerebellum, medulla, and left frontal lobe. The lesions remained nonenhancing without mass effect.

\section{Questions for consideration:}

1. What could have precipitated the change in her examination?

2. How would you manage this patient?

\section{GO TO SECTION 5}




\section{Section 5}

Immune reconstitution inflammatory syndrome (IRIS) should be suspected when a paradoxical worsening of neurologic deficits is noted after the initiation of cART. It is a rebound inflammatory response to a restored immune system, consisting of destruction of myelin by macrophages and CD8+ T lymphocytes. A retrospective review study of 54 PML-IRIS cases found that the majority of patients who develop IRIS do so within 12 weeks of cART initiation, and predictive factors include a rapid decrease in HIV viral load, a low CD4 count, and lack of prior exposure to antiretroviral drugs. ${ }^{6}$ Typically, brain MRI in PML-IRIS reveals $\mathrm{T} 2$ hyperintense lesions that are often, but not always, contrast enhancing. Contrast enhancement may also be transient and therefore missed at the time of evaluation. ${ }^{1}$ Treatment of IRIS consists of a short course of IV corticosteroids, although no definite conclusions have been reached regarding their efficacy. It is unclear if clinical outcome differs between patients with PML-IRIS treated or untreated by corticosteroids, but they are often used by clinicians in severe cases. When deciding to treat patients with IRIS, clinicians must also consider the necessity of allowing restoration of the immune response for the underlying PML. ${ }^{7}$

Our patient presented with several of the known predictive factors of PML-IRIS. Progression of PML may explain her worsening clinical status, but given the severity of her symptoms and apparent response to antiretroviral therapy with a now undetectable viral load, she was treated empirically for IRIS. However, in light of a lack of evident benefit of the treatment as well as development of steroid-induced agitation, the family requested that further treatment be withheld. The patient died in hospice shortly after.

\section{Author contributions}

Christine Lu: drafting/revising the manuscript, accepts responsibility for conduct of research and final approval. Lili Velickovic Ostojic: drafting/revising the manuscript, study concept or design, analysis or interpretation of data, accepts responsibility for conduct of research and final approval, acquisition of data. Hernan Nicolas Lemus: drafting/revising the manuscript, study concept or design, analysis or interpretation of data, accepts responsibility for conduct of research and final approval, acquisition of data.

\section{Study funding}

No targeted funding reported.

\section{Disclosure}

The authors report no disclosures relevant to the manuscript. Go to Neurology.org/N for full disclosures.

\section{References}

1. Sahraian MA, Radue EW, Eshaghi A, Besliu S, Minagar A. Progressive multifocal leukoencephalopathy: a review of the neuroimaging features and differential diagnosis. Eur J Neurol 2012;19:1060-1069.

2. Tan CS, Koralnik IJ. Progressive multifocal leukoencephalopathy and other disorders caused by JC virus: clinical features and pathogenesis. Lancet Neurol 2010;9:425-437.

3. Berger JR, Aksamit AJ, Clifford DB, et al. PML diagnostic criteria. Neurology 2013;80: 1430-1438.

4. Engsig FN, Hansen $\mathrm{AB}$, Omland $\mathrm{LH}$, et al. Incidence, clinical presentation, and outcome of progressive multifocal leukoencephalopathy in HIV-infected patients during the highly active antiretroviral therapy era: a nationwide cohort study. J Infect Dis 2009; 199:77-83.

5. Marzocchetti A, Tompkins T, Clifford DB, et al. Determinants of survival in progressive multifocal leukoencephalopathy. Neurology 2009;73:1551-1558.

6. Tan K, Roda R, Ostrow L, McArthur J, Nath A. PML-IRIS in patients with HIV infection: clinical manifestations and treatment with steroids. Neurology 2009;72:1458-1464.

7. Fournier A, Martin-Blondel G, Lechapt-Zalcman E, et al. Immune reconstitution inflammatory syndrome unmasking or worsening AIDS-related progressive multifocal leukoencephalopathy: a literature review. Front Immunol 2017;8:577.

8. Jackson AC. Viral Infections of the Human Nervous System. Basel: Birkhauser Verlag GmbH: Springer; 2013.

9. Bag AK, Curé JK, Chapman PR, Roberson GH, Shah R. JC virus infection of the brain. AJNR Am J Neuroradiol 2010;31:1564-1576. 


\section{Neurology}

\section{Clinical Reasoning: A 52-year-old woman with 3 weeks of progressive gait ataxia and dysarthria}

Christine Lu, Lili Velickovic Ostojic and Hernan Nicolas Lemus

Neurology 2018;90;e985-e989

DOI 10.1212/WNL.0000000000005122

\section{This information is current as of March 12, 2018}

\section{Updated Information \&} Services

References

Subspecialty Collections

Permissions \& Licensing

Reprints including high resolution figures, can be found at: http://n.neurology.org/content/90/11/e985.full

This article cites 8 articles, 4 of which you can access for free at: http://n.neurology.org/content/90/11/e985.full\#ref-list-1

This article, along with others on similar topics, appears in the following collection(s):

\section{HIV}

http://n.neurology.org/cgi/collection/hiv

Viral infections

http://n.neurology.org/cgi/collection/viral_infections

Information about reproducing this article in parts (figures,tables) or in its entirety can be found online at:

http://www.neurology.org/about/about_the_journal\#permissions

Information about ordering reprints can be found online:

http://n.neurology.org/subscribers/advertise

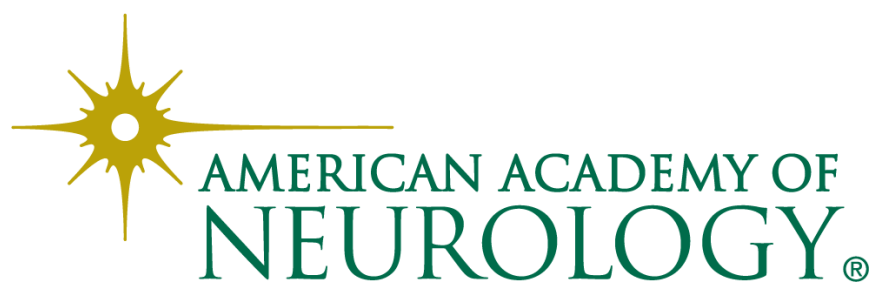

